\title{
An Empirical Investigation In To Literature In English As A Support To Students Improved Performance In English Language At The Senior Secondary School Certificate Examination In Yobe State - Nigeria.
}

\author{
Hafsat Ahmad Abubakar,*B.Ed., Ma. \\ Department of General Studies School of General Studies The Federal Polytechnic Damaturu, Nigeria
}

\begin{abstract}
Language provides manhis intelligent form, categorization and consistency. Languagecreates culture, whereas literature functions as the collection house of culture. In factrelatively few researchers'appear to focus on literature as an aid to learning of language as assert by (Adeniyi, 2010). The purpose of this investigation therefore, is with the former. That is, it asks the question "How does the study of English Literature aid performance in English Language at the School Certificate Examination in Yobe State?" It is hoped that the outcome of the research on factors affecting attainment in English Language in Yobe State and the recommendations may offer a working tool for tutors and supervisory authorities and general public.Especially, with current public outreach and disappointment about the poor performance of students in English Language at the Secondary School level of the state.
\end{abstract}

\section{Background To The Study}

The colonial masters introduced the English language to Nigerians as they did not value the native languages. The English Language was seemed as the only official way of communication, teaching and training people to serve in the government. The schools $\square$ curricula were designed after the culture, education and history of the colonialists communicated through the use of the English language; this gave the citizens no other alternative than to attain the English language. Therefore, the English Language became the countries' lingua franca. That is the language of "convenience $\square$ for interconnecting with different ethic groups being trained and connected in a common language. The superiority, proficiency and effectiveness of Nigeria's school's curriculum depend on the English language as theofficial language. This was the outcome of injurious disposition of the colonialists to our natives' languages; in fact supervisor of schools, once dismissed the vernacular as "only interesting to the comparative philologist and never expected to become of any applied use to civilization" English became a second language in the country owing to the multi-lingual nature of the nation and it assisted in the amalgamation of the nation. In Nigerian homes, children were educated from the foundation to speak the English language as a language of communication. This study is fundamentally designedto examine the role of English literature as an aid for improved students' performance in school certificate examinations in Yobe state. The English Language in the school Curriculum as it is affected by literature. Variouslanguage and linguists and theorists have repeatedly attached high premium on authenticacquaintance with the grammatical structures and composition of language, if certain criteria must be accomplished in it. On the other hand, the critics of literary theorists and opponentsfrequently put forward a purely literary response to the question of learning and teaching language. For them, realization in language abilities such asspeaking, writing, listening and reading largelydepends on theextent, of skilled and proficient teaching in literature as suggested by (Adonis 1974). In fact "literature entails of certain specified forms, varieties, andcollections of language. (And as such), the study of literature is basically a study of language ( Olatunde, 2010). While the findings of research areenormous with discussions on, and studies relating to the linguistic point of view, comparativelylimited studies seem to center on the literary point of view. The concern of this study therefore is with the latter. That is, it asks the question "How does the study of English Literature aid effectiveachievement in English Language at the Senior Secondary School Examination in Yobe State? It is expected that the findings of this study of factors affecting attainment in English language may offer a working tool for YobeState Teachers, and candidates in senior Secondary Schools Examinations and in English language in precise.

\section{Research Design}

The policy of West African Examination Council does not, allowed the disclose of raw scores obtained by candidates at the school cert Examination, for this reasons the design of the research categorized into two of passes, 'credit and above' and 'ordinary pass' grade. This was adopted as criteria for statistical judging 
achievementin English Language. Hence, the research design for this study relatedindependently the percentage of 'credit and above' grade and of 'ordinary pass' grade earned in English Literature and English Language papers. The used statistic T-test tool was adopted to test the level of significance of differencesamong the groups. The adoption of T-test was neededsince the population grouped in to two related groups (Glass and Stanley1970).

\section{Area of Study}

The area for this study was Damaturu. In Yobe State, there are both government and private schools. Though, the students' performance in the public schools is the one mostly used by supervisory regulatory authority in the country for planning. Hence, all the schools used in this study are public schools. The necessity for the coverage of the research in taking this pattern was informed by the lack outing of majority of public schools in the state at both SSCEand NECO in recent past.

\section{Population}

The population for this study was 1366 students from twelve secondary schools in Yobe State who took the SSCE examination of June 2013. There were eight boys' schools and four girls' schools. Out of these 1366 students, 870 students sat for both English Language and English Literature Papers and 496 students sat for only English Language. This population is so chosenbecause it is at this level that any course that is intended at improving theproficiency oflanguage and study skills of the students can best be measured. Secondly, it is at this level that the students are anticipated to have had adequate exposure in English which is probably give them comprehensive linguistic proficiency and so can be obtain admission to higher institutions where they experimentcomplex studies in English Language.

\section{Sample And Sampling Technique}

The sample for the study was drawn from secondary school candidates who sat for the 2013 SSCE examination. To ensure homogeneity, all the 1366 students from twelve secondary schools in Yobe State who took the SSCE in English Language and Literature were considered for the stud. In selecting the sample, the researcher gave every student an opportunity. This methodguarantees effective appraisal without likely hood of bias. The same technique was adopted to assistin grouping candidates who wrotefor both Literature and English Language and English Languageonly (Alemmal 1986).

\section{Instruments For Data Collection}

The researcher used two instruments these are investigation. (a)The students' SSCE 2013 results in both English Language and English Literature from the result broadsheet sent to Educational Resource Centre(ERC). (b) The Observation Checklist. The observation checklist was used to certify that every result fitted to the right student and that the genuine number that sat for the examination had their results with the correct subject title against their names. This is aimed at reducing the possibility of investigating wrong subject.

\section{Validation Of Instrument}

To ensure the validity of the instrument the researcher adopted the used, the broad score sheet acquired from ERC was related with the ones in the sample schools of study and also the state Ministry of Education. There was also the verification of this result from the internet. The validity of the tool used was therefore established as the most correct and most related as it does not give room for discrepancies.

\section{Reliability Of Instrument}

The instrument is reliable because all the tested students whose results were on the broad result sheet had the opportunity of being tested which brought about the result under study.

\section{Method Of Data Collection}

Anofficial letter of request to Educational Resource Centre and the Ministry of Education for the result sheet of all those who sat for both English and Literature during the 2013 SSCE examination inthe affected 12 schools was written and presented. The result sheets were obtained and related with what was in the internet. In each of the pairs compared, the DF was 48 and 3. Accordingly, theexpected F value was 64.5 for the calculated $\mathrm{F}$ values for the pairs compared were each less than 3 . This means that the groups were identical.

\section{Method Of Data Analysis}

The policy of West African Examination Council does not, allowed; the scores obtained by candidates in the examinations to bedisclose. As such, the broad result sheet was collected and classified into two groups of passes, 'ordinary pass' grade and credit and above grade. These were used as statistical data for mediating 
achievement in English language alone and in both English Language and Literature. The T-test with its zvalues was adopted to find different levels of significance. The descriptive technique was also used as a method for analysis and explanation.

VI. Results

Table 1 below represent candidate with grade Credit and Above' Grade in English Language by Type of Candidate

\begin{tabular}{|l|l|l|l|l|}
\hline Category & Lang/Lit & Lang & \\
\hline Category & Boys & Girls & Boys & Girls \\
\hline Credit \& above & $\mathbf{6 7}$ & $\mathbf{7 3}$ & $\mathbf{4 3}$ & $\mathbf{3 1}$ \\
\hline Ordinary & $\mathbf{9 6}$ & $\mathbf{5 2}$ & $\mathbf{1 5 6}$ & $\mathbf{2 2}$ \\
\hline Scores Diff (d) & $\mathbf{2 9}$ & $\mathbf{2 1}$ & $\mathbf{1 1 3}$ & $\mathbf{1 0}$ \\
\hline Z & $\mathbf{0 . 0 4 9 6}$ & $-\mathbf{0 . 2 6 7 7}$ & $\mathbf{3 . 3 8 0 9}$ & $\mathbf{- 0 . 7 0 3 9}$ \\
\hline
\end{tabular}

$\mathrm{Zi}, \mathrm{Z} 2, \mathrm{Z} 4<\mathrm{Z} 5 \%=>$ not significant $=$ ordinary pass not less than credit.

$\mathrm{Z3}, \mathrm{Z} 5 \%=>$ significant pass greater than credit

$$
\begin{aligned}
& \text { Since } Z=\frac{d-\bar{d}}{s_{d}}, \quad \bar{d}=\frac{\sum d}{n}=29.75, \quad n=4 . \\
& S_{\mathrm{d}}=\sqrt{\frac{\sum(d-\bar{d})^{2}}{n(n-1)}}=24.7382 .
\end{aligned}
$$

Z-values table was used to test thesignificance level. From the above table we can observed the distribution of 'credit and above' grade in English Language as 496 representing 67\% for boys and 73\% for girls respectively who sat for both English Language and English Literature papers, and $43 \%$ representing boys and $31 \%$ representing girls respectively who sat for only the English Language paper. It will be remembered that categories of passes are, 'credit and above' and 'ordinary pass' grades, were adopted as a measure of performance in English Language. The results analyses are presented independently for each of these standardsmeasures as indicated in the respective table.

Table 2: Z-values for Comparing Candidates Who Obtained 'Credit and Above'Grade in English Language and Literature

\begin{tabular}{|l|l|l|}
\hline Category & Lang/Lit & Lang \\
\hline Boys & 162 & 198 \\
\hline Girls & 128 & 53 \\
\hline Scores Diff $(\mathbf{d})$ & 34 & 145 \\
\hline $\mathbf{z}$ & -1.0 & 1.0 \\
\hline
\end{tabular}

$$
\begin{aligned}
& \bar{d}=89.5, \quad n=2 \quad S_{d}=\sqrt{\frac{\sum(\mathrm{d}-\overline{\mathrm{d}})^{2}}{\mathrm{n}(\mathrm{n}-1)}}=55.5 \\
& Z_{1}=-1.0<Z_{5 \%} \quad=1.65 \\
& Z_{2}=1.0<Z_{5 \%}
\end{aligned}
$$

Boys are not better than girls.

Lang: Thepercentageof Credit and above' grade performance in English Language Boys had significantly higher, Lit/Lang: Boys $(Z=0.04, p<.01$. And, Lang/Lit: Girls had a proportion of 'Credit and above' Grade in English Language that varied significantly from that of Lang: Boys $(Z=3.38, p<0.1)$. Other performance was found to be encouraging.

Table 3 Z-values for Comparing Candidates who obtained 'Ordinary Pass' Grade in English Language

\begin{tabular}{|l|l|l|}
\hline Category & Lang/Lit & Lang \\
\hline LangB & 67 & 43 \\
\hline LangG & 77 & 32 \\
\hline Scores Diff (d) & 10 & 11 \\
\hline $\mathbf{z}$ & -1 & 1 \\
\hline
\end{tabular}




$$
\begin{array}{lll}
\bar{d}=10.5, & n=2 & S_{d}=\sqrt{\frac{\sum(\mathrm{d}-\overline{\mathrm{d}})^{2}}{\mathrm{n}(\mathrm{n}-1)}}=0.5 \\
Z_{1}=\frac{0.5}{0.5}=-1 & <Z_{5 \%} & \\
Z_{2}=\frac{0.5}{0.5}=1 & <Z_{5 \%} &
\end{array}
$$

The Girls are not greater than the Boys.

The final table shows the Z-values resulting from comparison of scores of candidates in Lang/Lit versus Lang, who obtained 'Ordinary Pass' Grade in English Language;however, two of the comparisons were significant. Lang: Boys had highly significant proportion of ('Ordinary Pass' Grade) in English Language than Lang/Lit: Boys $(\mathrm{Z}=6.82, \mathrm{p}<.01)$ and as well as Lang/Lit: Girls $(\mathrm{Z}=3.93, \mathrm{p}<.01)$. The remaining comparisons were not significant.

\section{Discussion Of Findings}

The Analysis of the results from this study revealedthree major issues. To start with, thepercentage of female students who has an Ordinary Pass Grade in English Language at the SSCE Examination is greater than that of male candidates, regardlessthe fact that the candidates offer English Literature or not . The findings were in line with the findings of Binda S.I. (2010), related the results in Mathematics of candidates in co-educational and uni-sex schools. He related this variance to the "popular myth" regarding the weakness of females in Mathematics and in regard to the findingsfrom this study we might be said to replicate the common myth about the dominance of females in the arts related subjects, one of which is English Language.Secondly, the outcomesappear to point out that at least over 43 percent of Yobe State candidates obtain failing grades in English Language at the SSCE Examination. This indicate theterrible state of affairs, as earlier researchers have acknowledged, since a pass in English Language is compulsory for gaining a full certificate while a credit is entry prerequisite to the University and polytechnics/colleges in the country. By implications, those candidatescannot easily secure admission in to higher institutions of learning in the country. This augments to social complications when they perceive that expressive capacity does not essentially indicate their understanding of language. Finally, the statistical result appears to poise that the study of English Literature does not automatically or meaningfullyinspired the student's proficiency in English Language. This finding should cause concern to personsinvolved in teaching Language and Literature in our secondary schools. Thissupported thepositions of Geoffrey (2002).University of Beninconference for teachers of English held in October 2011 the Literature working party suggested for the incorporation of teaching of English Language and English Literature in the school curriculum. It was argued that this will improve the pupil's capacity to understand and integrate but would also support his effort at attaining fluency in English Language usage. The inference here is that English Language and English Literature should to supplement each other. That these outcomes do not bear out this theory may be owing to somereasons. We would agree that a student's cultural upbringing, his environment and academic capabilities considerablyimpact his performance in all parts of study. Joyce (2001) argued that certainpupils come to the subject prepared with a great level of awareness while others come from environments where they have never been encouraged to express an original thought. These are some of the difficulties that tutors of English Language and English Literature have to contend with. In fact success would mean that the student would growself-confidence to express a reasonable opinion, enter creatively into the understandings of others and thus increase practice in using the language which should resulted to greater ability in performance the written word as argued by (Tom 2008). We must therefore, consider the requirements of Literature paper in which the pupils are anticipated to show comprehensive knowledge of a partial number of texts which they have read previously. Here pupils have to struggle to grip facts and the language of literature in context.

\section{Conclusion}

This studyexamined whether the study of English Literature impacts student's proficiency in English Language. The overturned Stanine Grades in English Language O-Level, obtainable from the SSCE 2013 result broadsheet of 870 candidates who sat for both English Language and English Literature papers were related with those of 496 students who sat for only the English Language; the results showed that the study of English Literature does not support the study of English Language. Though, researchers are of the view that the study of English Language and English Literature must to supplementary to each other. Certain reasons that appear to donate to this discrepancyconcerning theory and results are high-lighted for further study.

\section{Recommendations}

It is largely recognized that Literature should not be separated from real life and as such the range and choice of Literature texts should be significantly broadened. For instance, it could include Literature which 
compacts with modern challenges, Literature that is adequately close to the student's understanding that would engender interest in the subject. By this, we do not mean a replacement of Nigerian names for English names with no effort at making the experiences described appropriate to our real life; neither do we mean the prohibiting of Shakespeare from the syllabus; but, we would like to see Shakespeare premeditated not simply in the historical background as an workout in documentary analysis, but from the point of view of current times. Such a method would inspire students to form sentiments which they can express rather than memorize views of other people. Also, if the scope is expanded, the students should be inspired to read separate from classroom, thus increase their vocabulary and support them to advancetheir awareness with the constructions of the Language. Quite often, questions asked in the SSCE paper design to test the student's capacity both to remember and to understand facts at a exact level; little emphasis is employed on analysis and response to these facts. It is clear that it is in these areas that the student would formulate his own ideas, express them and thus prove his proficiency in the Language. With a change in emphasis, we might well see an end to lines memorized from texts, inappropriately quoted memorized modelanswers and paragraphs lifted out of ill-digested criticisms by other people. Literature should be encouraged because it strengthens Language conducts, as Language ceases to be approached as a system of symbols to be attained purely for passing 'English Papers but as a instrument for appreciating and communicating the whole variety of human thought. There can be no doubt that in Yobe State where the atmosphere does not foster the student's understanding with the Language; the student of Literature has no option than to look Literature for the much desirable exposure to the Language. Both the teacher of English Literature and the examination body should be conscious of this in order to shape their efforts to accomplish the desires of the learners. Likewise, it appears clearly that except substantial thought is given to the approaches of teaching and evaluation of bothEnglish Literature and English Language, we cannot use performance at school cert examinations as a effective measure of the student's capacity to use the English Language.

\section{References}

[1]. Adeniyi, P.O. (2010). Resources and materials for teaching english language innigerian primary and secondary school. In applied social dimensions oflanguage use and teaching in africa. Ghana: The University press, Capecoast.

[2]. Alemal, C. (1986). Educational research 4th Ed. Englewood cliffs: PrenticeHall.

[3]. Awuzie, U.A. (2010). Language, Culture and the Nigerian situation. In Journal ofnigerian languages and culture: 12:1 March,2010.

[4]. Adonis, F. (1974:393). English literature as a passive catalyst to success inenglish language at the G.C.E. O-Level Examination: In West AfricanJournal of Education XVII: 3, October 1974

[5]. Geoffrey, L. (2002). A Communicative Grammar of English (Third Edition) NewYork: Longman.

[6]. Glass, G. (1973). Statistical methods in education and psychology. Eaglewood Cliffs,

[7]. N.J. Prentice-Hall.Joyce, A.C. (2001). Writing and Grammar Communicationin Action. NewJersey: Prentice-Hall.

[8]. Labor, A.F. (1973). Co-education and mathematics attainment in western area inSierra Leone. Sierra Leone Journal of Education. $8: 2,1973$

[9]. Moody, H.L. B. (1971). The teaching of literature in developing countries.London: Longman Group Ltd.

[10]. Olatunde, J.A. (2010). Language, Culture and the Nigerian situation.In Journal ofNigerian Languages and Culture. 12:1, March, 2010 .

[11]. Tom, S. (2008). The Language of Success. New York: AMACOM. 